\title{
Body Image Distortion and Dissatisfaction in a Mexican sample
}

\section{Distorsión e Insatisfacción con la Imagen corporal en una muestra de mexicanos}

\author{
Meza Peña, Cecilia ${ }^{1, *}$ and Pompa Guajardo, Edith ${ }^{1}$
}

\begin{abstract}
:
The present study analyzes the relationship between body image satisfaction and distortion with the body mass index (BMI). Participants were 540 students from different schools of middle and higher level from Monterrey, Mexico; age ranked from 16 to 25 years. The anthropometric data (weight, height, BMI) were evaluated and later the participants completed the Figure Rating Scale, where they reported the self-perception of their current body image and their ideal body image. The results show difference between the real and ideal body image, and between the real body image and the BMI group. It also reveals that the higher the BMI the greater distortion in the body image, moreover women show the greatest dissatisfaction with their body image. In conclusion, dissatisfaction and distortion in the perception of body image is present in people living with overweight and obesity, but men and women face this phenomenon in a different form. Mental and health professionals can take advantage of this discomfort when implementing strategies to control obesity, while working in building a healthy and realistic body image.
\end{abstract}

Keywords: body image, distortion, dissatisfaction, body mass index, body silhouettes.

Palabras clave: imagen corporal, distorsión, insatisfacción, índice de masa corporal, siluetas corporales.

\footnotetext{
${ }^{1}$ Universidad Autónoma de Nuevo León. Monterrey, Nuevo León, México.

*Correspondencia: cecilia.mezapn@uanl.edu.mx
} 
In Mexico, obesity is a serious health problem occupying the second place worldwide in adult obesity and the first place in terms of overweight population (Organisation for Economic Co-operation and Development OECD, 2014). Results of the National Survey of Health and Nutrition of Half-Way ENSANUT 2016- (Instituto Nacional de Salud Pública, 2016), indicate that there is a prevalence of $36.3 \%$ of overweight and obesity in adolescents.

Among the different psychological constructs that are analyzed around the phenomenon of obesity, body image is considered a key element which negatively affects those who live with this health problem (Wardle \& Cooke, 2005).

Concerns about body image is something that is learned within a specific historical and cultural context, where standards of beauty change. In the actual Western culture, the media promote thinness as a standard of beauty, and several studies focus on analyzing the pressure perceived by women to lose weight and stay thin (Stice \& Shaw, 2002; Sypeck, Gray, \& Ahrens, 2004).

Body image is the perception that a person has of their own body, includes the aspects of incorporation and estimation of the size and shape of the body (Grogan, 2008), is a construct based on the conscious and unconscious representation of our body integrated by two dimensions: a social and an individual one(Aguado, 2004). In this way, the construction of body image is a complex process influenced by biological, psychological and social factors (Fitzsimmons, 2011; Fitzsimmons-, Harney, Koethler, Danzi, Riddell, \& Bardone, 2012).

There are two aspects of body image that have been studied extensively. By one side we have the distortion in the perception of the body image where people can overestimate or underestimate parts or their whole body, while the dissatisfaction with the figure or the concern for it, involves efforts to modify the body or behaviors that attempt against the individuals health. In other terms, there is a perceptive and a cognitive-affective dimension of body image (Garner \& Garfinkel, 1981, Carraça et al., 2012).

Due to the complexity of the body image construct and these different dimensions, there are several instruments that allow evaluating body dissatisfaction (Sarwer, Thompson, \& Cash, 2005), while others assess the distortion in the perception of body image (Gardner \& Brown, 2010; Pull \& Aguayo, 2011). In this way, there is evidence which emphasize that dissatisfaction with weight does not necessarily lead to dissatisfaction with the body (Flynn \& Fitzgibbon, 1998).

Dissatisfaction with body image is widely studied in relation to eating disorders, and in the last two decades, it has been studied in relation to overweight and obesity, with evidence of relationship in both directions (Sansone, Wiederman, \& Monteith 2001; Lim, Thomas, Bardwell \& Dimsdale, 2008; Mond, Van den Berg, Boutelle, Hannan, \& Neumar, 2011). In addition, there are numerous studies that show the relationship between body image dissatisfaction and other psychological disorders (Choi \& Choi, 2016).

In Mexico, body image has been studied through the use of body silhouettes. Some of the studies have been carried out in the adult population, confirming the correspondence between the BMI and the perception of body shape (Kaufer, Martinez, Goti, Ávila, 2006) while others point out that there is a great discrepancy between the ideal and the 
actual body shape, with no differences by gender (Muñoz, Zueck, Blanco, Chávez, \& Jasso, 2014). In the sense of validation, Stunkard's silhouettes have been used to assess the nutrition status in schoolchildren and adolescents. The study by Cortés-, Vallejo, Pérez-, \& Ortiz (2009) shows that silhouettes can be an effective measure for this purpose since children and adolescents who have concerns about their weight are better classified in the silhouettes, as well as they observe that at greater age they show greater precision.

Bobadilla and López (2014), have used the Stunkard's silhouettes in Mexican population to analyze the distortion between the real image and the perceived image, finding that women have a higher percentage of positive distortion, that is, they are perceived with greater weight than they have, while in men they found greater negative distortion. They notice the lack of studies analyzing the relationship between body image distortions depending on the weight status, particularly with overweight or obese persons. On the other hand, the silhouettes have been used in the ENSANUT 2012, and its analysis report that people who are diagnosed with overweight and obesity have less distortion in the perception of the silhouette that best represents them. This result show that in these weight groups, they have a realistic assessment of their health status when they have a previous diagnosis (Easton, Stephens \& Sicilia, 2017).

Works such as Acosta and Gómez (2003), as well as that of Muñozet al. (2014) have worked with the silhouettes in the sense of detecting dissatisfaction, reporting that Mexican women are more dissatisfied with their bodies than men, but they found that these dissatisfaction is similar to the reported in studies with Spanish women. Bunnell,
Cooper, Hertz, and Shenker (1992) observe that body dissatisfaction is related to subjective aspects of weight which better predict dietary behaviors than actual weight. This aspect should be explored in more detail as it can lead to risky eating behaviors.

There are other instruments similar to the silhouettes developed by Stunkard et al. in which we can mention the developed by Thompson and Gray (1995) and by Gómez, Granados, Jáuregui, Pineda, and Tafoya (2000). However, in the present study we opted for the silhouettes by Stunkard et al. since there is ample evidence of its use for evaluating dissatisfaction and distortion in the perception of body image. However, we could not find studies that analyze both aspects of body image in the same project, as well as there is little evidence of its use around obesity and even more in Mexican samples. We have found in different reports that the study of body image seems to be focused on problems of eating disorders, however, in the present paper we have focused on the work that warns about aspects of body image in overweight and obesity groups, noting the necessary study of this phenomenon, in the sense of dissatisfaction and distortion, since the evidence in this sense can be used to implement intervention strategies for obesity in Mexico, with a special attention to the work with the body image in those who live with this health problem. Thus, the present study has as objective to analyze the dissatisfaction and distortion in the perception of body image in Mexican adolescents, studying the differences according to sex and weight groups.

\section{Method}

The study used a quantitative approach with a descriptive and transversal survey design. 


\section{Participants}

The sample was integrated by 540 participants; of which $24.4 \%$ were men $(n=132)$ and $75.6 \%$ were women $(n=408)$. The ages of the participants were from 16 to 25 years, $(M=17.88, S D=1.47)$. The disparity of the sample reflects the proportion of students in the institutions where the study was conducted, which have $70 \%$ of female students. None of the participants were professional athletes and in the case of women none were pregnant or lactating at the time of the study. All were recruited from public educational institutions of middle and higher education. in the metropolitan area of Monterrey, Mexico. The institutions were chosen through convenience sampling.

\section{Instruments}

Figure Rating Scale (Stunkard, Sorensen, \& Schulsinger, 1983). This scale was originally developed and validated to evaluate body satisfaction, with images that range from thinness (silhouette 1) to severe obesity (silhouette 9) (Figure 1). The participant is asked to choose the number of the silhouette that he considers most similar to his/her real body appearance (perceived body PB) and also the number of the silhouette that he/she believes to be more similar to the physical appearance that he/she would like to have (ideal body IB) considered for his/her age. The reliability and validity of the scale has been reported in international studies and in Mexican population (Cortés, Vallejo, Pérez, \& Ortiz, 2009; Zanjani \& Goodarzi, 2007). The psychometric analysis of test reliability shows an adequate validity (Keshtkar et al., 2010). The difference between the two silhouettes (PB-IB) is interpreted as the degree of satisfaction-dissatisfaction with one's own body image. The greater the difference result, the greater the dissatisfaction. A positive difference indicates the dissatisfaction that the adolescent feels because he/she wants to be thinner while the negative difference represents the dissatisfaction he/she feels when there is a desire to be thicker; the null difference $(0)$ is interpreted as satisfaction (Acosta \& Gómez, 2003). In addition, the distortion in the perceived body image was calculated as the difference between the perceived BI and the real image (from the BMI weight group). Positive scores indicate that the person overestimate his/her body, while a negative score indicate an underestimation of the current size.

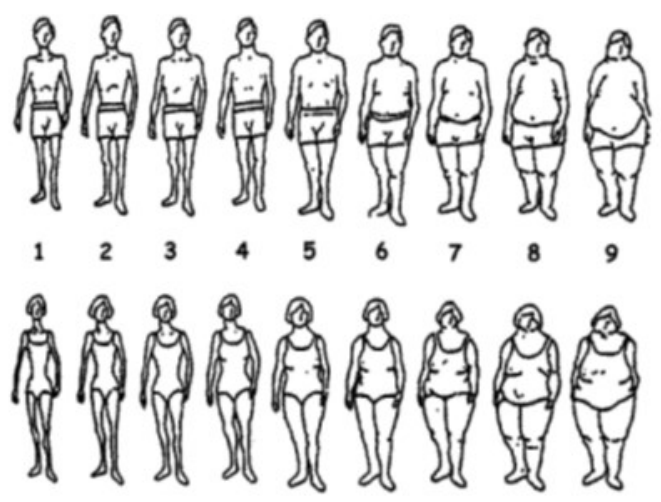

Figure 1. Stunkard Figure Rating Scale for males and females (Stunkard, Sorensen, \& Schulsinger, 1983).

Tanita Inner Scan BC 418 Impedancemeter Scale. This instrument has eight stainless steel electrodes to perform the analysis of body composition: 4 electrodes to position the feet. The total time spent per analysis is 30 seconds and allows a measurement of weight along with other indices such as body fat, body water, lean mass, visceral fat and body mass index. The weight groups 
were defined according to the criteria of the World Health Organization (WHO, 2014) for the BMI classification: low weight $\leq 19.99$; normal weight from 20 to 24.99 , overweight of 25-29.9 and obesity $\geq 30$.

Mechanical Stadiometer for children and adults SECA 216. A wall column stadiometer-scale- was used, with a measuring range of 200 centimeters, which allows measuring the size.

\section{Procedure}

The study was conducted with approval from the Research Office of the School of Psychology at the Universidad Autonoma de Nuevo Leon, and according to recommendations on ethics in research with human beings made by the American Psychological Association (2002) and the Mexican Society of Psychology (Sociedad Mexicana de Psicología, 2007).

Authors programmed meetings with principals from two public schools of upper middle (high school) and higher education in northern Mexico. Institutions were invited to participate in the research project, explaining clearly the main objectives.

In the high school case, we invited parents to a conference about adolescence, at the end of the same we presented the research project and ask for permission to invite the students to collaborate as participants. The study was carried out relying on the prior informed consent of parents in the case of being minor, and then adolescents were asked for voluntary participation. In the case of the institution of higher education, we ask for permission to the authorities of the nutrition and nursery colleges to access students at their classrooms and invite them to participate explaining the main objective of the study.

Once the informed consent was ob- tained from parents and adolescents, in both institutions the instruments were used in selfreport format and applications were made in the presence of evaluators. During the application, the objectives of the study were explained to participants, requesting their voluntary participation and guaranteeing the confidentiality of the information obtained, as well as the possibility of leaving the study at the time they wished without any repercussions. When participants finished filling out the instruments, we asked them to attend to the measurements registration (height and weight), which were made in a special office designated for this purpose in each institution using a Tanita scale and a stadiometer. The little space allowed an adequate control of the environment, controlling the entry and exit of participants and recording measurements to every person. All students were weighted shoeless. From 723 students who completed the forms, we finally analyzed data of 540 .

\section{Statistical analysis}

The characteristics of the participants were described using means, standard deviations and percentages. The BMI was calculated from the measurements of weight and height using the standard formula of weight in kilograms/ [height in meter ${ }^{2}$ ]), which corresponds to the Quetelet index (Quetelet, 1871). BMI itself was divided into four discrete groups according to established cut points $<20,20$ $24.99,25-29.9$ and $>30 \mathrm{~kg} / \mathrm{m} 2$ to categorize the participants as underweight, normal weight, overweight and obesity (WHO, 2014). The figures were classified as low weight (1 \& 2), normal weight ( $3 \& 4)$, overweight $(5,6 \& 7)$ and obesity $(8 \&$ \&) (Bhuiyan, Gustat, Srinivasan, \& Berenson, 2003; Nikniaz, Mahdavi, Amiri, Ostadrahimi, 
\& Nikniaz, 2016).

The normality of the distribution of the data was evaluated with the KolmogorovSmirnov test. Differences between weight groups were compared using the one-way ANOVA test. The Wilcoxon rank test was used for related samples to compare the real $\mathrm{BI}$ with the ideal, as well as the real BI with the BMI group. For the correlations, regression models were used, which allow to observe the association between the independent variables and the distortion of the body image (1- BI without distortion, 2- distorted BI) and dissatisfaction (1- dissatisfaction for being thinner; 2- dissatisfaction for being heavier). The level of statistical significance was estab- lished at an $\alpha$ of 0.05 .

\section{Results}

Table 1 shows the demographic and anthropometric characteristics of the participants, means and standard deviations of the continuous variables, and frequencies and percentages of the categorical ones are presented.

Table 2 shows the distribution of means and standard deviations of $\mathrm{PB}, \mathrm{IB}$, dissatisfaction with BI and distortion of BI in relation to weight categories.

To test the normality of the distribution, we used the Kolmogorov-Smirnov test in the variables of PB, IB and BMI, obtaining a $p$-value under .005. Then the Wilcoxon

Tabla 1.

Participant's characteristics

\begin{tabular}{ccccccc}
\hline Continuous & \multicolumn{2}{c}{ Total sample } & \multicolumn{2}{c}{ Men } & \multicolumn{2}{c}{ Women } \\
\cline { 4 - 7 } variables & $M$ & $S D$ & $M$ & $S D$ & $M$ & $S D$ \\
\hline Age & 18.5 & 7.787 & 18.91 & 4.77 & 18.37 & 8.53 \\
BMI & 23.29 & 5.96 & 24.07 & 7.51 & 22.98 & 5.23 \\
PB & 3.93 & 1.45 & 3.93 & 1.58 & 3.92 & 1.40 \\
IB & 3.35 & 0.87 & 3.63 & .860 & 3.25 & .858 \\
Categorical & Frequency & Percentage & Frequency & Percentage & Frequency & Percentage \\
variables & & 28.0 & 37 & 28.0 & 115 & 28.2 \\
\hline Under Weight & 151 & 37.8 & 33 & 25.0 & 169 & 41.4 \\
Normal & 204 & 22.0 & 35 & 26.5 & 86 & 21.1 \\
Weight & 119 & 12.2 & 27 & 20.5 & 38 & 9.3 \\
Overweight & 66 & 56.3 & 62 & 47.0 & 242 & 59.3 \\
Obesity & 304 & 19.6 & 42 & 31.8 & 64 & 15.7 \\
BI thinner & 106 & 24.1 & 28 & 21.2 & 102 & 25.0 \\
BI heavier & 130 & 74.3 & 99 & 75.0 & 302 & 74.0 \\
Satisfied with & 25.7 & 33 & 25.0 & 106 & 26.0 \\
BI & 401 & 139 & 25.0 &
\end{tabular}

Note . $\mathrm{BMI}=$ body mass index, $\mathrm{PB}=$ perceived body, $\mathrm{IB}=$ ideal body, $\mathrm{BI}=$ body image, $M=$ mean, $S D=$ standard deviation 
signed rank test was used for group contrast. Table 3 shows the groups' difference analysis in the total sample and by gender groups. It can be observed in the group of participants that the difference between real and ideal BI is significant, so the null hypothesis of equali- ty between the groups is rejected. When comparing gender groups, we obtain a probability of error less than $5 \%$ in the contrast, concluding that in the $95 \%$ of men and women that are compared, there is a difference between the real BI and the ideal one. On the other

Table 2.

Means and Standard Deviations of variables by weight groups

\begin{tabular}{|c|c|c|c|c|c|c|c|c|c|}
\hline & \multicolumn{2}{|c|}{$\begin{array}{l}\text { Under } \\
\text { Weight } \\
n=151\end{array}$} & \multicolumn{2}{|c|}{$\begin{array}{l}\text { Normal } \\
\text { Weight } \\
n=204\end{array}$} & \multicolumn{2}{|c|}{$\begin{array}{c}\text { Overweight } \\
n=119\end{array}$} & \multicolumn{2}{|c|}{$\begin{array}{c}\text { Obesity } \\
n=66\end{array}$} & \multirow[t]{2}{*}{$p$-value* } \\
\hline & $M$ & $S D$ & $M$ & $S D$ & $M$ & $S D$ & $M$ & $S D$ & \\
\hline PB & $\begin{array}{c}1.5 \\
2\end{array}$ & .56 & 2.19 & .51 & $\begin{array}{c}2.6 \\
1\end{array}$ & .56 & 2.84 & .37 & .000 \\
\hline IB & $\begin{array}{c}1.8 \\
1\end{array}$ & .45 & 1.86 & .43 & $\begin{array}{c}1.9 \\
4\end{array}$ & .39 & 2.09 & .53 & .021 \\
\hline Dissatisfied & -.64 & 1.25 & .69 & 1.17 & $\begin{array}{c}1.2 \\
9\end{array}$ & 1.35 & 1.71 & .73 & .000 \\
\hline Distortion & .52 & .56 & .19 & .51 & -.39 & .56 & -1.15 & .37 & .000 \\
\hline
\end{tabular}

Note. $\mathrm{PB}=$ perceived body, $\mathrm{IB}=$ ideal body, $M=$ mean, $S D=$ standard deviation, $* p$-value of one-way ANOVA.

Table 3.

Differences between Ideal Body Image and BMI

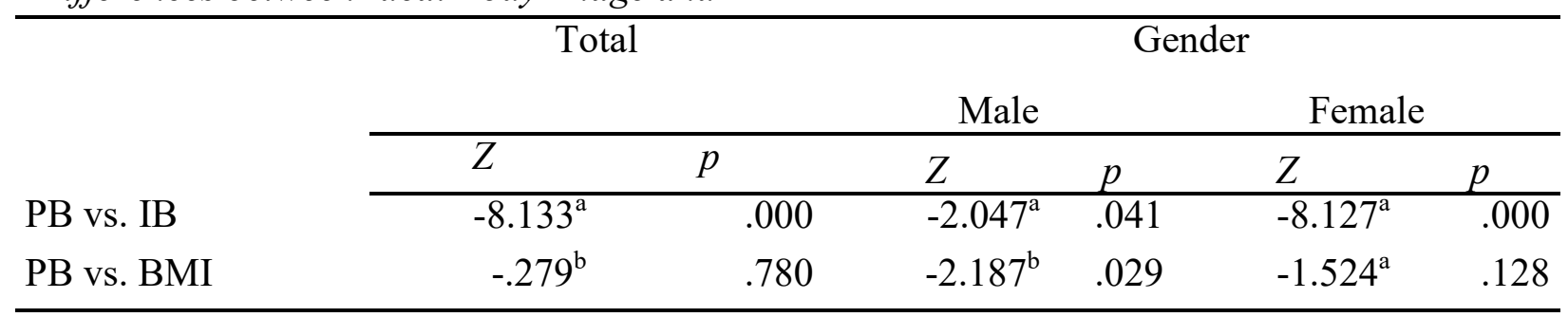

Note. $\mathrm{PB}=$ perceived body, $\mathrm{IB}=$ ideal body, $\mathrm{BMI}=$ body mass index, $\mathrm{Z}=$ Wilcoxon score, $\mathrm{p}=$ value of probability, ${ }^{\mathrm{a}}=$ based on positive ranks, ${ }^{b}=$ based on negative ranks.

hand, only men show a statistically significant difference between the PB and the BMI group to which their weight corresponds.

A regression model is generated for the association between the distortion of body image and age, BMI, gender, marital status. Through the successive steps method, is generated a model that predicts $51 \%$ in the varia- ble of body image distortion, and where only the BMI is significant (power of $23 \%, p$ $=.000)$. The results of a second model by the method of successive steps are shown in Table 4 .

Similarly, a regression model is generated for the association between body image dissatisfaction and age, BMI, gender, marital 
status. By the successive steps method, a model is generated that predicts in a $37 \%$ the variable of body image dissatisfaction, and where sex and BMI are significant (power of $53 \%$ and $31 \%$ respectively, $p=.000$ ). A second model by the method of successive steps confirms that body dissatisfaction is predicted by BMI and by gender (Table 5).

\section{Discussión}

The results of this study indicate that no matter the participant is over weighted or in a

Table 4.

Prediction of perceived body image distortion.

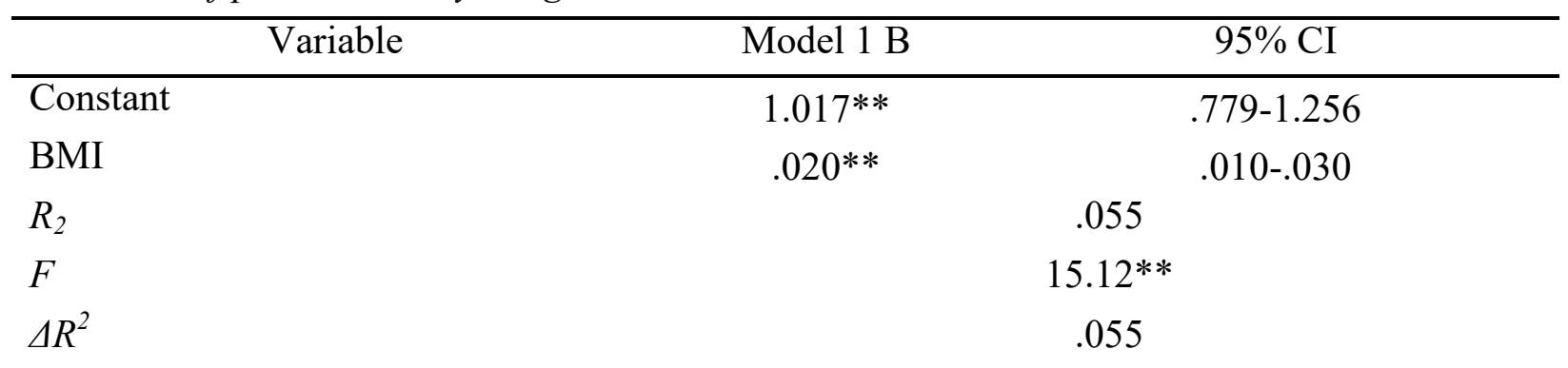

Note. $\mathrm{BMI}=$, body mass index, $\mathrm{N}=540, \mathrm{CI}=$ confidence interval. ${ }^{* *} p<.01$

Table 5.

Prediction of Body Image Dissatisfaction

\begin{tabular}{lcccc}
\hline Variable & Model $1 B$ & Model 2 $B$ & \multicolumn{2}{c}{$95 \%$ CI } \\
\hline Constant & $2.150^{* *}$ & $2.668^{* *}$ & 2.400 & 2.935 \\
BMI & $-.037^{* *}$ & $-.038^{* *}$ & -.046 & -.030 \\
Gender & & $-.295^{* *}$ & -.400 & -.190 \\
$R_{2}$ & .270 & & .366 & \\
$F$ & $75.52^{* *}$ & & $58.712^{* *}$ & \\
$\Delta R^{2}$ & & .096 & \\
$\Delta F$ & & $30.853^{* *}$ \\
\hline
\end{tabular}

Note. $\mathrm{BMI}=$ body mass index, $\mathrm{N}=540, \mathrm{CI}=$ confidence interval. ${ }^{* *} p<.01$

rank of normal weight, there is a dissatisfaction with their bodies, prevailing the ideal figure that in most of the cases is thinner than the one they have. However, when analyzing the differences between the perceived and the ideal image in the gender groups, we can observe that women wants to have a thinner fig- ure, while men opts for a larger one.

Coinciding with these findings, Trejo, Castro, Facio, Mollinedo, and Valdez (2010) observed that the greatest body dissatisfaction is related to higher BMI values, mainly in women. In addition, in a large study by Ramos, Pérez, Liberal, and Latorre (2003), it is 
observed that about half of the adolescents studied would like to be thinner, although they also note that the percentage of males with body image dissatisfaction is higher in contrast to women. In line with our study, Díaz and Blanquez (2001) report that that there is a high percentage of women who do not accept their body image and feel dissatisfied with it.

In contrast to the findings of the present study, a study in adolescents shows a greater acceptance of body image in women than in men, even with the desire of women to have a larger figure (López, Díaz, and Smith, 2018), as well as Sánchez, Pulido, Sánchez, Amado, and Miguel (2018), report that there is no difference between the ideal and the real figure in their sample, since both measures agree. Other study, show correlations between the perceived figure and the size of the body, but in the particular case of African-American women there is an underestimation of the body (Sutcliffe, Schultz, Brannock, Giardiello, and Platz, 2015).

On the other hand, Fitzsimmons et al. (2012) refer that the perception of body size between men and women may differ because culturally women usually give greater importance to the ideal of thinness, while in men it is more appropriate to have a stronger or more muscular body.

Pétré et al. (2016) point out that in the design of strategies for the management of obesity, the focus should not only be on the BMI indicator, but in addition to include other variables that are important, as the perceptual and subjective factors. In this sense, body image distortion and dissatisfaction should be included in the intervention to improve the quality of life. Their study shows conformity with body image at older age of obese people, and how health professionals should ask if this compliance is for satisfaction or conformism, that is, for resignation-acceptance of their obesity or for the lack of results in their efforts to lose weight.

\section{Conclusion}

The objective of the present study was to analyze the dissatisfaction and distortion in the perception of body image in Mexican adolescents, in which we found that women are more aware of their actual body size, meaning they have less distortion in the perception of their bodies compared to man, but both gender groups show dissatisfaction with their bodies. By weight groups, we can see that people who live with overweight and obesity show greater distortion as well as dissatisfaction with their body image.

Furthermore, dissatisfaction with body image in overweight women can be explained by the social pressure they live by the cultural standards of thinness, which take them to be on a diet and remain thin. In men these standards demand athletic and beefy bodies. In both cases, to have a previous diagnosis of a weight problem can conduct to a realistic assessment of the weight status, meaning no distortion in the perception of the body image, but the aspects of dissatisfaction with the body image go beyond the scope of a weight status.

As literature remarks, the dissatisfaction with the body image can predict the dietary behaviors, and mental and health professionals can take advantage of this discomfort to implement strategies that can lead to lose weight in a healthier way, while working in the construction of a healthy and realistic body image. To be aware of the actual size, is the first step to be motivated to do something in the case we need to improve our health. Lack of awareness is like denying we have a health problem, and health professionals working in the obesity problem of Mexico, often struggle against Mexican culture values which positively not only accept but celebrate to have some extra pounds. To educate our culture that thinness is not only about social acceptance, but a health issue, is something we need to still work on.

The present study has limitations that 
should be considered in future research, and which limit the scope of the results, in which we must point out that the sample used has the characteristic of being non-probabilistic, so the extrapolation of the results to a similar population requires its contrast. The age ranges are limited, so it's recommended to expand them to obtain valid results for the population. In addition, it's recommended in future research to find a probabilistic sample representative. We understand this study as a starting point for future research, since the number of studies that analyze both the dissatisfaction and the distortion of the body image is still limited, and fewer the studies where these variables are analyzed based on weight status, as well as we also think that it can be complemented with other instruments that allow a better understanding of the population under scope.

\section{References}

Acosta, M.V., \& Gómez, G. (2003). Insatisfacción corporal y seguimiento de dieta: una comparación transcultural entre adolescentes de España y México. International Journal of Clinical Health Psychology, 3(1), 9-21.

Aguado, J. C. 2004. Cuerpo humano e imagen corporal. México: Facultad de Medicina UNAM-IIA.

American Psychological Association (2002). Ethical principles of psychologists and code of conduct. American Psychologist, 57 (12), 1060-1073. doi:10.1037/0003-066X.57.12.1060

Bhuiyan, A. R., Gustat, J., Srinivasan, S. R., \& Berenson, G. S. (2003). Differences in body shape representations among young adults from a biracial (black-white), semirural community: The Bogalusa Heart Study. American Journal of Epidemiology, 158 (8), 792-797. doi: 10.1093/ aje/kwg218

Bobadilla, S., \& López, A. (2014). Distorsión de imagen corporal percibida e imaginada. Un posible factor para la obesidad y el sobrepeso en mexicanos. Revista Médica del Instituto Mexicano del Seguro Social, 52(4), 408-414.

Bunnell, D.W., Cooper, P.J., Hertz, S., \& Shenker, I.R. (1992). Body shape concerns among adolescents. International Journal of Eating Disorders, 11(1), 79-83. doi:10.1002/1098-108X
(199201)11:1<79::AID-

EAT2260110111>3.0.CO;2-V

Carraça, E. V., Markland, D., Silva, M. N., Coutinho, S. R., Vieira, P. N., Minderico, C. S., ... Teixeira, P. J. (2012). Physical activity predicts changes in body image during obesity treatment in women. Medicine and Science in Sport and Exercise, 44(8), 1604-1612. doi: 10.1249/ MSS.0b013e31824d922a

Choi, E., \& Choi, I. (2016). The associations between body dissatisfaction, body figure, self-esteem, and depressed mood in adolescents in the United States and Korea: A moderated mediation analysis. Journal of Adolescence, 53, 249-259. doi: 10.1016/j.adolescence.2016.10.007

Cortés, G., Vallejo, N.L., Pérez, D., \& Ortiz, L. (2009). Utilidad de siluetas corporales en la evaluación del estado nutricional en escolares y adolescentes de la Ciudad de México. Boletín Médico del Hospital Infantil de México, 66 (6), 511-521.

Díaz, J., \& Blanquez, M.P. (2001). Corporalidad y síntomas depresivos en adolescentes. Revista Psiquiatría y Psicología del Niño y Adolescente, 1(3), 16-25.

Easton, J.A., Stephens, C.R., \& Sicilia, H.R. (2017). An analysis of real, self-perceived, and desired BMI: is there a need for regular screening to correct misperceptions and motivate weight reduction? Front. Public Health, 5(12), 1-8. doi: 10.3389/fpubh.2017.00012

Fitzsimmons, E. (2011). Social psychological theories of disordered eating in college women: review and integration. Clinical Psychology Review, 31(7), 1224-1237. doi: 10.1016/ j.cpr.2011.07.011

Fitzsimmons, E.E., Harney, M.B., Koethler, L.G., Danzi, L.E., Riddell, M.K., \& Bardone, A.M. (2012). Explaining the relation between thin ideal internalization and body dissatisfaction among college women: The roles of social comparison and body surveillance. Body Image, 9 (1), 40-49. doi:10.1016/j.bodyim.2011.09.002

Flynn, K.J., \& Fitzgibbon, M. (1998). Body images and obesity risk among black females: a review of the literature. Annual Behavioral Medicine, 20(1), 13-24. doi: 10.1007/BF02893804

Gardner, R.M., \& Brown, D.L. (2010). Body image assessment: a review of figural drawing scales. Personality and Individual Differences, 48(2), 107-111. doi:10.1016/j.paid.2009.08.017

Garner, D.M., \& Garfinkel, P.E. (1981). Body image in 
anorexia nervosa: measurement theory and clinical implications. International Journal of Psychiatry and Medicine, 11(3), 263-284.

Gómez, G., Granados, A., Jáuregui, J., Pineda, G., \& Tafoya, S.A. (2000). Un instrumento para medir imagen corporal: versión computarizada y de papel y lápiz. Revista Mexicana de Psicología, $17(1), 89-99$.

Grogan, S. (2008). Body image: understanding body dissatisfaction in men, women and children. London, U.K.: Routledge.

Instituto Nacional de Salud Pública (2016). Encuesta Nacional de Salud y Nutrición de Medio Camino 2016 (ENSANUT 2016). Cuernavaca, México, Instituto Nacional de Salud Pública.

Kaufer-Horwitz, M., Martínez, J., Goti-Rodríguez, L.M., \& Ávila-Rosas, H. (2006). Association between measured BMI and self perceived body size in Mexican adults. Annals of Human Biology, 33(5-6), 536-545. doi:10.1080/03014460600909281

Keshtkar, A., Semnani, S., Pourshams, A., Khademi, H., Roshandel, G., Boffetta, P., \& Malekzadeh, R. (2010). Pictogram use was validated for estimating individual's body mass index. Journal of Clinical Epidemiology, 63(6), 655-659. doi: 10.1016/j.jclinepi.2009.08.014

Lim, W., Thomas, K.S., Bardwell, W.A., \& Dimsdale, J.E. (2008). Which measures of obesity are related to depressive symptoms and in whom? Psychosomatics, 49(1), 23-28. doi:10.1176/ appi.psy.49.1.23

López, G.F., Díaz, A., \& Smith, L. (2018). Análisis de imagen corporal y obesidad mediante las siluetas de Stunkard en niños y adolescentes españoles de 3 a 18 años. Anales de Psicología, 34(1), 167-172. doi: 10.6018/analesps.34.1.294781

Mond, J., Van den Berg, P.A., Boutelle, K., Hannan, P., \& Neumar-, D. (2011). Obesity, body dissatisfaction, and emotional well-being in early and late adolescence: findings from the project EAT study. The Journal of Adolescent Health, 48(4), 373-378. doi:10.1016/j.jadohealth .2010.07.022

Muñoz-, F., Zueck-, M.C., Blanco, J.R., Chávez, A, \& Jasso, J. (2014). Body image perception of Mexican youth: a gender comparison, Education Journal, 3(5), 261-265. doi: 10.11648/ j.edu. 20140305.11

Nikniaz, Z., Mahdavi, R., Amiri, S. Ostadrahimi, A., \& Nikniaz, L. (2016). Factors associated with body image dissatisfaction and distortion among Iranian women. Eating Behaviors, 22, 5 9. doi:10.1016/j.eatbeh.2016.03.018

Organisation for Economic Co-Operation and Development [OCDE] (2014). Dataset: non-medical determinants of health: body weight. Recuperado de http://stats.oecd.org/index.aspx? DataSetCode $=$ HEALTH_STAT

Pétré, B., Scheen, A.J., Ziegler, O., Donneau, A.F., Dardenne, N., Husson, E... \& Guillaume, M. (2016). Body image discrepancy and subjective norm as mediators and moderators of the relationship between body mass index and quality of life. Patient Preference and Adherence, 10, 2261-2270. doi: 10.2147/PPA.S112639

Pull, C.B., \& Aguayo, G.A. (2011). Assessment of body image perception and attitudes in obesity. Current Opinion in Psychiatry, 24(1), 41-48. doi: 10.1097/YCO.0b013e328341418c

Quetelet, A. L. J. (1871). Anthropométrie, ou Mesure des différentes facultés de l'homme. Bruxelles: C. Muquardt.

Ramos, P., Pérez de Eulate, L., Liberal, S., \& Latorre, M. (2003). La imagen corporal en relación con los TCA en adolescentes vascos de 12 a 18 años. Revista de Psicodidáctica, 15-16, 65-74.

Sánchez, P.A., Pulido, J.J., Sánchez, D., Amado, D., \& Miguel, F. (2018). The importance of body satisfaction to physical self-concept and body mass index in Spanish adolescents. International Journal of Psychology, 1-9. doi: 10.1002/ ijop. 12488

Sansone, M.A., Wiederman, M.W., \& Monteith, D. (2001). Obesity, borderline personality and body image among women in a psychiatric outpatient setting. International Journal of Eating Disorder, 29(1), 76-79. doi:10.1002/1098-108X (200101)29:1<76::AID-EAT12>3.0.CO;2-O

Sarwer, D.B., Thompson, J.K., \& Cash T.F. (2005). Body image and obesity in adulthood. Psychiatric Clinics of North America, 28(1), 69-87. doi:10.1016/j.psc.2004.09.002

Sociedad Mexicana de Psicología (2007). Código ético del psicólogo (4 edición). México, DF: Editorial Trillas.

Stice, E., \& Shaw, H.E. (2002). Role of body dissatisfaction in the onset and maintenance of eating pathology. A synthesis of research findings. Journal of Psychosomatic Research, 53 (5), 985 -993. doi:10.1016/S0022-3999(02)00488-9

Stunkard, A., Sorensen, T., \& Schulsinger, F. (1983). Use of the Danish adoption register for the 
study of obesity and thinness. In S. Kety, L. Roland, R. Sidman, \& S. Matthysse (Eds.), The genetics of neurological and psychiatric disorders (pp. 115-120). New York, Raven Press.

Sutcliffe, C.G., Schultz, K., Brannock, J.M., Giardiello, F.M., \& Platz, E.A. (2015). Do people know whether they are overweight? Concordance of self-reported, interviewer-observed, and measured body size. Cancer Causes Control, 26(1), 91-98. doi:10.1007/s10552-014-0487-y

Sypeck, M.F., Gray, J.J., \& Ahrens, A.H. (2004). No longer just a pretty face: fashion magazines' depictions of ideal female beauty from 1959 to 1999. International Journal of Eating Disorders, 36(3), 342-347. doi:10.1002/eat.20039

Thompson, M.A., \& Gray, J.J. (1995).Development and validation of a new body-image assessment scale. Journal of Personality A ssessment, 64(2), 258-269. doi:10.1207/s15327752jpa6402_6

Trejo, P.M., Castro, D., Facio, A., Mollinedo, F.E., \& Valdez, I.G. (2010). Dissatisfaction with de body shape associated to the body mass index in adolescents. Revista Cubana de Enfermería, 26 (3), 144-154. http://www.bvs.sld.cu/revistas/ enf/vol26_3_10/enf07310.pdf

Wardle, J., \& Cooke, L. (2005). The impact of obesity on psychological well-being. Best Practice and Research: Clinical Endocrinology and Metabolism, 19(3), 421-440. doi:10.1016/j.beem.2005.04.006

World Health Organisation (2014). Obesity and overweight. Available online: http://www.who.int/ mediacentre/factsheets/fs311/en/index.html (accessed on March 25, 2016)

Zanjani, Z., \& Goodarzi, M.A. (2007). Reliability and validity of Figure Rating Scale in Shiraz students. Mental Health Principles, 10(2), 149-155. 